\title{
Inactivation and Photorepair of Enteric Pathogenic Microorganisms with Ultraviolet Irradiation
}

\author{
Xuexiang Hu, Shujie Geng, Xiujuan Wang, and Chun $\mathrm{Hu}^{\star}$ \\ State Key Laboratory of Environmental Aquatic Chemistry, Research Center for Eco-Environmental Sciences, \\ Chinese Academy of Sciences, Beijing, China.
}

Received: October 28, $2010 \quad$ Accepted in revised form: August 29, 2011

\begin{abstract}
Ultraviolet inactivation of enteric pathogenic microorganisms, including Shigella dysenteriae, Salmonella typhimurium, and human rotavirus (HRV-Wa) and somatic coliphages (MS2 and T4), was investigated in different water samples. Significant differences in the sensitivity of the bacteria and viruses to ultraviolet radiation were observed. Viruses were more resistant to ultraviolet disinfection than all the enteric bacteria tested in this study. With the exception of S. typhimurium, which showed flattening and tailing, strong first-order relationships between the logarithm of survival and the ultraviolet dose were observed. While S. dysenteriae and S. typhimurium were found to undergo photoreactivation after ultraviolet exposure, the photoreactivation decreased significantly with higher ultraviolet doses. Moreover, the inactivated bacteria exhibited different photoreactivation rates with different water samples. Combination of a low ultraviolet dose and a low concentration of chlorine not only inhibited the photoreactivation of ultraviolet-damaged bacteria but also effectively inactivated the bacteria.
\end{abstract}

Key words: UV disinfection; photoreactivation; chlorine; enteric pathogenic bacteria; inactivation.

\section{Introduction}

W ATERBORNE PATHOGENS HAVE a devastating effect on public health. Intestinal parasitic infections and diarrheal diseases caused by waterborne bacteria and enteric viruses are a leading cause of malnutrition, since food eaten by people sickened by waterborne pathogens is poorly digested (Lima et al., 2000; Montgomery and Elimelech, 2007; Shannon et al., 2008). Traditional water disinfection processes rely heavily on chemical disinfectants, such as chlorine, which produce chemical disinfection by-products in finished drinking water (Muellner et al., 2007). Because it does not produce chemical disinfection by-products and has excellent biocidal properties, ultraviolet (UV) disinfection is now highly regarded as an alternative to chlorination for the treatment of drinking water (Quek and $\mathrm{Hu}$, 2008; Wolfe, 1990). However, because UV radiation from the sun is present in the environment, natural defense mechanisms have evolved in bacteria and other microorganisms that allow UVinactivated microorganisms to reverse UV-induced damage through such repair pathways as photoreactivation and dark

*Corresponding author: State Key Laboratory of Environmental Aquatic Chemistry, Research Center for Eco-Environmental Sciences, Chinese Academy of Sciences, Beijing, 100085, China. Phone: +86-106284-9628; Fax: +86-10-6292-3541; E-mail: huchun@rcees.ac.cn repair (Koivunen and Heinonen-Tanski, 2005; Quek and Hu, 2008). Since these defense mechanisms are obstacles to safe disinfection levels and the application of UV disinfection, scientists have studied photoreactivation and dark repair following UV treatment extensively in the past few decades (Quek and $\mathrm{Hu}, 2008$; Quek et al., 2006). Just as different strains of Escherichia coli have different repair abilities, different types of bacteria exhibit different sensitivities to UV applications and have different repair abilities. A microorganism's UV resistance depends on the UV dose applied and its ability to protect itself from UV light and to repair damages (Sommer et al., 2001). It seems clear that knowledge of the UV sensitivity of important health-related microorganisms will lead to improvements in the design of future UV processes.

Because waterborne pathogenic Salmonella typhimurium, Shigella dysenteriae, and human rotavirus (HRV-Wa) can cause bloody diarrhea and death, they pose a severe public health risk. There have been, however, very few studies of the inactivation of these bacteria by UV light and the ability of the bacteria to repair themselves after exposure. For this study, $S$. typhimurium, S. dysenteriae, and rotavirus were selected to evaluate UV disinfection. Their inactivation kinetics and photorepair characteristics in different water samples were investigated, and the use of chlorine to inhibit photoreactivation was evaluated. As the final step, a UV-based disinfection process was proposed. 
Table 1. Main Chemical Characteristics of Test Water Samples

\begin{tabular}{lccccccc}
\hline Parameter & $p H$ & DOC $(m g / L)$ & $U_{254 n m}\left(\mathrm{~cm}^{-1}\right)$ & $\mathrm{Cl}^{-}(\mathrm{mg} / \mathrm{L})$ & $\mathrm{SO}_{4}^{2-}(\mathrm{mg} / \mathrm{L})$ & $\mathrm{NO}_{3}{ }^{-}(\mathrm{mg} / \mathrm{L})$ & ${\text { Alkalinity }\left(\mathrm{HCO}_{3}{ }^{-}, \mathrm{mM}^{2}\right)}$ \\
\hline PBS & 7.2 & - & - & - & - & - & - \\
DW & 8.00 & 1.90 & 0.0230 & 12.6 & 34.8 & 7.48 & 1.50 \\
SW & 8.25 & 4.60 & 0.0525 & 12.4 & 42.0 & 3.30 & 2.80 \\
\hline
\end{tabular}

\section{Materials and Methods}

\section{Preparation and enumeration of microorganisms}

Bacteriophage MS2 and the bacterial host strain E. coli (ATCC 15597) were purchased from the American Type Culture Collection. Bacteriophage T4 and the bacterial host cells E. coli B were provided by the Wuhan Institute of Virology, Chinese Academy of Sciences. Enteropathogenic bacteria $S$. dysenteriae and S. typhimurium were obtained from the Institute of Microbiology, Chinese Academy of Sciences.

$E$. coli and $S$. dysenteriae were inoculated into a nutrient broth medium, while $S$. typhimurium was maintained on tryptone soy broth (TSB) (Hu et al., 2010). HRV-Wa stocks were propagated, concentrated, and purified, using methods previously described by Jean et al. (2002). Propagation of MS2 and T4 coliphage was accomplished by the double-layer agar technique (Simonet et al., 2006).

During the experiment, an aliquot of the reaction suspensions was withdrawn at various reaction times. The bacteria were immediately diluted with a $0.9 \%$ saline solution, while bacteriophages were diluted with phosphate buffered saline (PBS) and rotavirus were diluted with Dulbecco's modified Eagle medium (DMEM). The bacterial concentration of S. dysenteriae, S. typhimurium, and E. coli were determined by the spread plate method after 48 hours of incubation at $37^{\circ} \mathrm{C}$. After incubation, the plates were counted, and the counts were averaged and recorded as colony-forming units per milliter $(\mathrm{CFU} / \mathrm{mL})$. Infectivity titers of HRV-Wa were enumerated by determining the $50 \%$ tissue culture infectious dose (TCID50), using the method described by Jean et al. (2002). The viable concentration of bacteriophages MS2 and T4 was achieved using the double agar layer method (Simonet et al., 2006). All counts were done in duplicate.

\section{Water samples}

Local surface water (SW) was collected from the Miyun reservoir in Beijing. Treated water samples were obtained from a local municipal drinking water treatment plant (DW) in Beijing at a sampling point after sand filtration. Samples were filtered through a $0.45 \mu \mathrm{m}$ nylon membrane, and stored at $4^{\circ} \mathrm{C}$ prior to use. The UV-inactivation of microorganisms was accomplished in PBS( $0.01 \mathrm{~mol} / \mathrm{L}, \mathrm{pH} 7.2)$. The water quality of the three water matrices is presented in Table 1.

\section{Experimental procedures}

UV irradiation. The UV disinfection experiments were performed with a bench-scale collimated beam apparatus, consisting of a low-pressure mercury lamp that produced UV light at a wavelength of $253.7 \mathrm{~nm}$ (11 W, Beijing Lighting Research Institute). Sterile $60 \mathrm{~mm}$ petri dishes were filled with a $20 \mathrm{~mL}$ suspension of the microorganisms in different water samples. The suspensions were stirred with a magnetic stirrer while being exposed to UV light. Exposure times were calculated based on the UV dose each suspension required and the average intensity of the radiation (Bolton and Linden, 2003). At the appropriate times, $0.5 \mathrm{~mL}$ of suspension was removed to determine the bacteria concentration.

Photoreactivation. For photoreactivation, the petri dishes containing the UV-irradiated bacteria were covered and stirred continuously under a fluorescent lamp with a light intensity of $0.066 \mathrm{~mW} / \mathrm{cm}^{2}$ at a wavelength of $360 \mathrm{~nm}$ for 3 hours. The percentage of photoreactivation was computed, as defined below:

$$
\begin{aligned}
& \text { percentage photoreactivation }(\%)= \\
& \frac{\text { No. of cells photoreactivated }}{\text { No. of cells inactivated by UV }} \times 100 \%
\end{aligned}
$$

Inhibition of photoreactivation. After UV irradiation, a desired concentration of chlorine ( $1 \mathrm{mg} / \mathrm{L}$ to $2 \mathrm{mg} / \mathrm{L}$ ) was immediately added to the samples, and the treated samples were then placed under fluorescent light for 3 to 4 hours. All experiments were repeated three times at room temperature $\left(25^{\circ} \mathrm{C} \pm 2^{\circ} \mathrm{C}\right)$.

\section{Results and Discussion}

\section{UV inactivation of enteric pathogenic microorganisms}

Figure 1 shows the inactivation kinetics of the various microorganisms following UV disinfection in PBS at room temperature. Because the analysis of HRV-Wa is a complex process, somatic coliphages MS2 and T4 were selected as the model viruses. As shown in Fig. 1, except for S. typhimurium, the very high linear correlation coefficient $\left(r^{2}>0.95\right)$ of the regression analysis indicates a strong first-order relationship

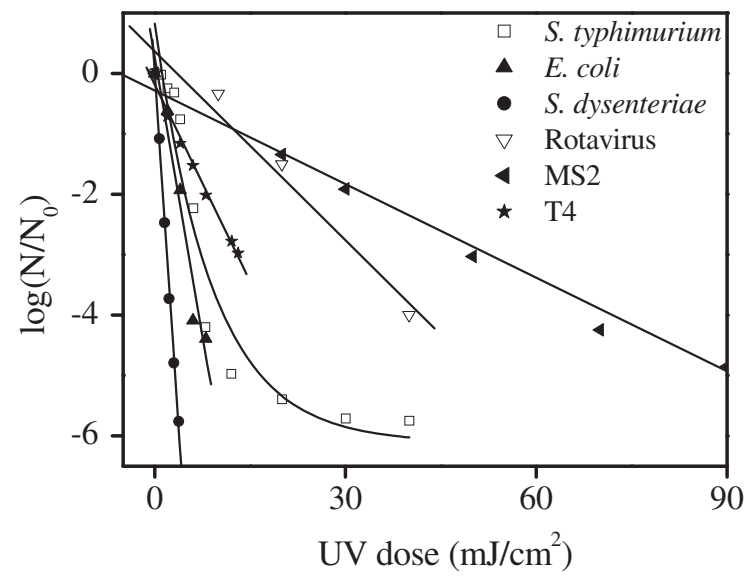

FIG. 1. Ultraviolet (UV) inactivation of microorganisms in phosphate buffered saline (PBS). 


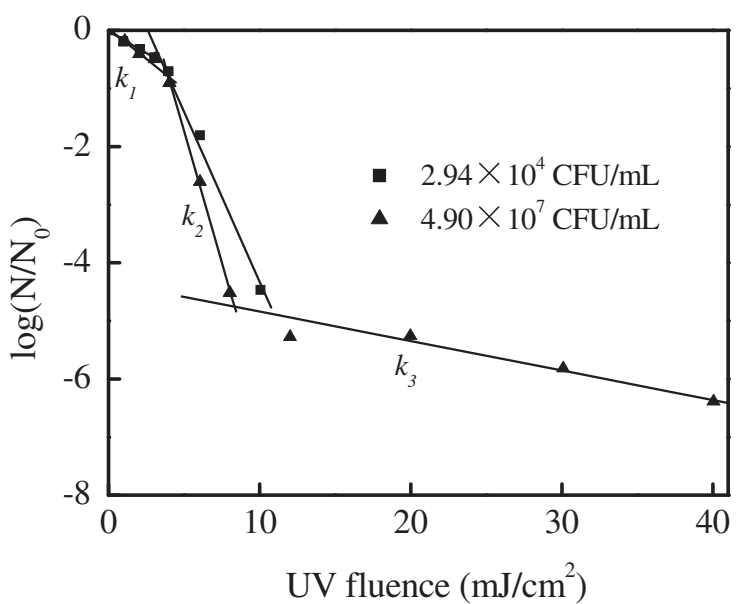

FIG. 2. UV inactivation of $S$. typhiumrium with different starting populations. CFU, colony-forming units.

between the logarithm survival rate $(\log )$ and the UV dose. First-order $k$ was $0.4353 \mathrm{~cm}^{2} / \mathrm{mJ}$ for $E$. coli, $1.5614 \mathrm{~cm}^{2} / \mathrm{mJ}$ for S. dysenteriae, $0.10423 \mathrm{~cm}^{2} / \mathrm{mJ}$ for rotavirus and $0.0516 \mathrm{~cm}^{2} /$ $\mathrm{mJ}$ for MS2. Of all the tested bacteria, S. dysenteriae was the most sensitive to UV disinfection. S. typhimurium was more UV resistant than $E$. coli and $S$. dysenteriae, which was inactivated $\sim 5.71 \mathrm{log}$ at a UV dose of $40 \mathrm{~mJ} / \mathrm{cm}^{2}$. The results show that $E$. coli cannot indicate the disinfection efficiency of S. typhimurium in drinking water systems. Furthermore, the dose response data indicate that rotaviruses are more resistant to UV disinfection than all the tested enteric bacteria. As shown in Fig. 1, bacteriophage T4 was more sensitive to UV irradiation than rotavirus. Of the enteroviruses and enteric bacteria used in this study, MS2 exhibited the least susceptibility to UV light, suggesting that it is a good surrogate for disinfection.

As shown in Fig. 2, at a concentration of $10^{7} \mathrm{CFU} / \mathrm{mL}$, S. typhimurium showed three distinct phases of inactivation kinetics. Initially, a shoulder is observed at a low UV dose of $4 \mathrm{~mJ} / \mathrm{cm}^{2}$. Subsequently, a first-order linear relationship is observed between the log and a UV dose between $4 \mathrm{~mJ} / \mathrm{cm}^{2}$ and $8 \mathrm{~mJ} / \mathrm{cm}^{2}$. With UV doses above $8 \mathrm{~mJ} / \mathrm{cm}^{2}$, a reduced inactivation rate was observed and tailing phenomenon occurred. The characteristic kinetic constants for the first, second, and third inactivation phases were $0.2094,0.9041$, and $0.0508 \mathrm{~cm}^{2} / \mathrm{mJ}$, respectively. The same inactivation response was observed when the initial population densities of $S$. $t y$ phimurium were $10^{4} \mathrm{CFU} / \mathrm{mL}$, but the tailing phenomenon did not occur. The results confirmed that aggregation of $S$. typhimurim suspension during UV treatment resulted in the tailing phase of the inactivation. Furthermore, no significant difference in PBS, DW, and SW water samples was observed for the inactivation of the tested bacteria, as shown Fig. 3.

\section{Photoreactivation of enteric bacteria inactivated by UV}

Since a virus does not have repair enzymes by itself (Furuta et al., 1997), the photoreactivation of HRV-Wa did not occur after UV irradiation. However, the repair of bacteria under a fluorescent lamp was investigated in this study. Figure 4 illustrates the photoreactivation kinetics of bacteria after exposure to different UV doses. The photoreactivation rates of
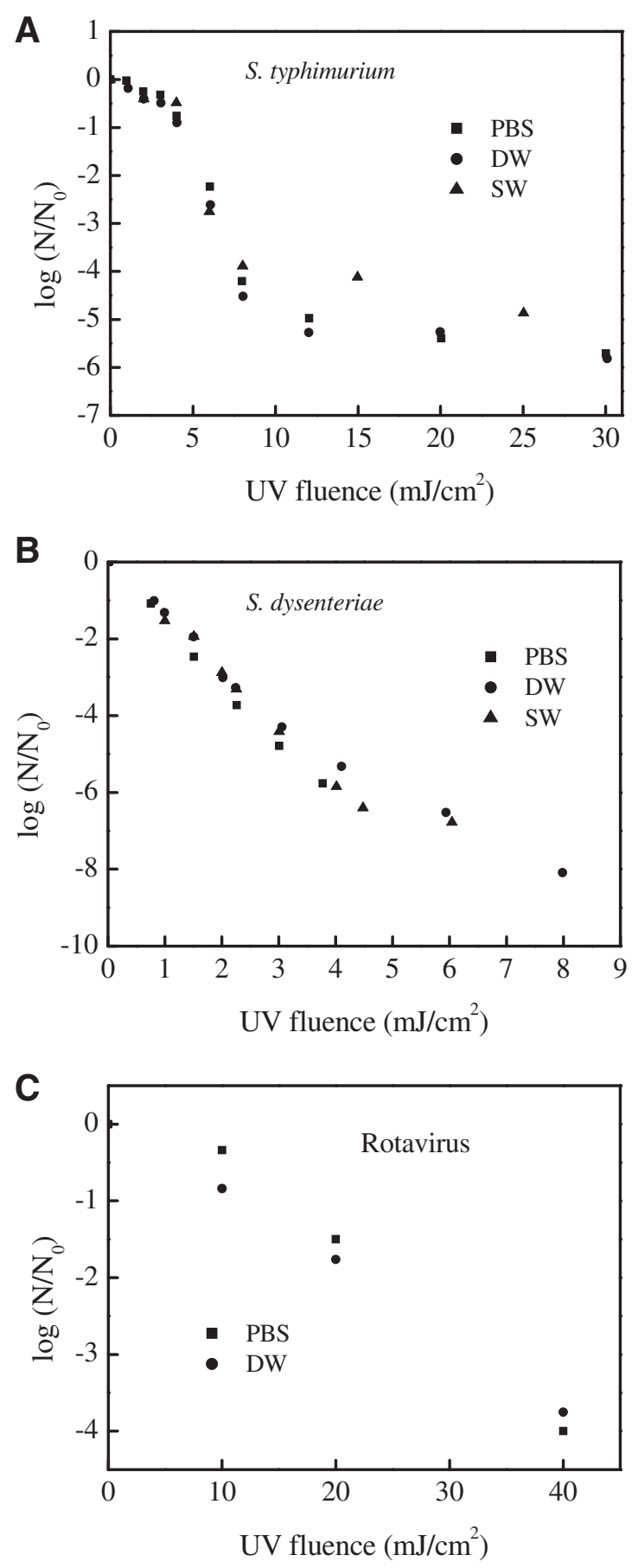

FIG. 3. UV dose-response curves of the tested bacteria and virus in various water matrices. (A) S. typhimurium; (B) S. dysenteriae; (C) rotavirus. DW, treated drinking water; SW, local surface water.

the three UV inactivated bacteria decreased with increasing UV doses. At the beginning stage, the induction period, the UV damaged bacteria exhibited imperceptible reactivation, then rapid exponential growth. As shown in Fig. 4, for the $E$. coli inactivated by a UV dose of $8 \mathrm{~mJ} / \mathrm{cm}^{2}$, the induction period was $\sim 30 \mathrm{~min}$. With longer times, E. coli repair increased rapidly, and photoreactivation reached the maximum level of $2.28 \%$ after $180 \mathrm{~min}$. However, the photoreactivation levels of 


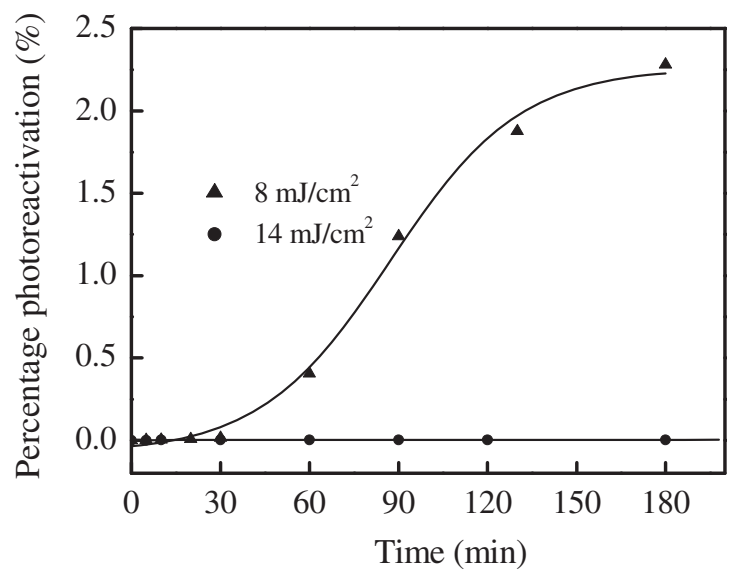

FIG. 4. Photoreactivation kinetics of E. coli after exposure to different UV doses in DW sample.

E. coli inactivated by a UV dose of $14 \mathrm{~mJ} / \mathrm{cm}^{2}$ were much lower. Only $0.45 \log E$. coli were reactivated under otherwise identical conditions. The higher UV dose would seem to induce greater damage to the DNA, decreasing the repair ability of E. coli. Supplementary Fig. S1 shows a similar phenomenon was observed for $S$. typhimurium and S. dysenteriae. The results suggest that higher UV doses should be applied for completely eliminating photoreactivation when drinking water is disinfected with UV light.

As shown in Fig. 5, after a UV dose of $8 \mathrm{~mJ} / \mathrm{cm}^{2}$, the photoreactivation level of E. coli in 3 hours was about $7.28 \%$, $2.28 \%, 2.58 \%$ in PBS, DW, and SW, respectively. The level of photoreactivation in PBS was higher than that in the two water samples. It may be that there are some photosensitizers, such as humic acid, $\mathrm{NO}_{3}{ }^{-}$, in water that can be excited by light to generate reactive oxygen species, inhibiting the bacterial repair.

\section{Inhibition of bacterial photorepair with chlorine}

The effects of different chlorine concentrations on the photorepair of $S$. dysenteriae are shown in Fig. 6A. Four log of $S$. dysenteriae was inactivated by a UV dose of $4 \mathrm{~mJ} / \mathrm{cm}^{2}$, and the residual S. dysenteriae was $3.59 \mathrm{log}$. At $120 \mathrm{~min}$ without the

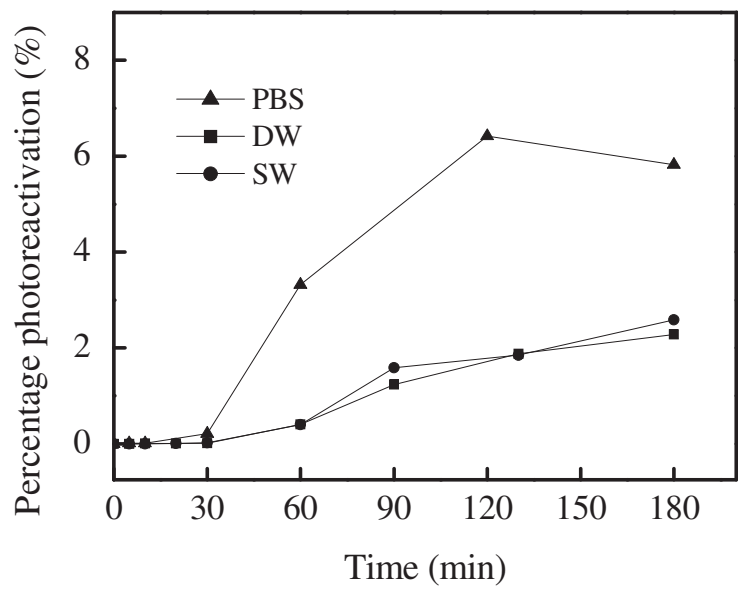

FIG. 5. Photoreactivation kinetics of E. coli in different water samples after exposed to $8 \mathrm{~mJ} / \mathrm{cm}^{2} \mathrm{UV}$.
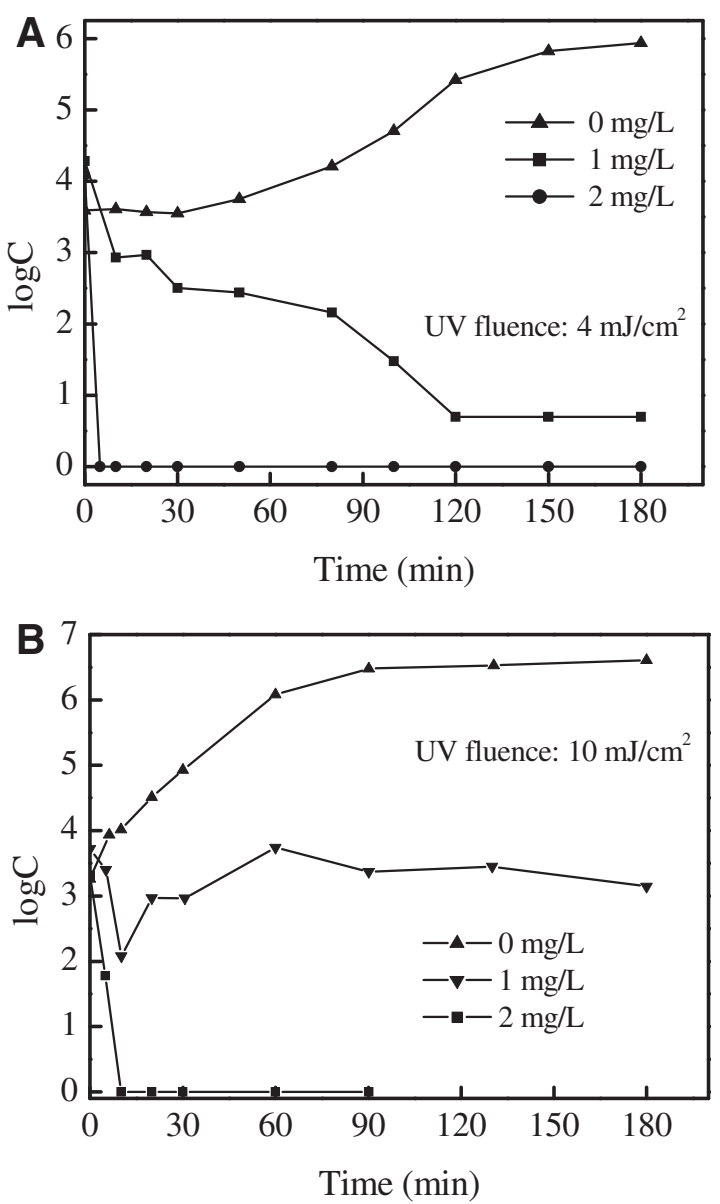

FIG. 6. Effect of chlorine dosage on the photoreactivation of enteric bacteria after UV disinfection. (A) S. dysenteriae. (B) S. typhimurium.

addition of chlorine, $2.13 \log$ of $S$. dysenteriae were reactivated. In contrast, the photoreactivation was completely inhibited and the residual $S$. dysenteriae was almost completely inactivated at $120 \mathrm{~min}$ with the addition of $1 \mathrm{mg} / \mathrm{L}$ chlorine. At a chlorine concentration of $2 \mathrm{mg} / \mathrm{L}$, the residual $S$. dysenteriae was inactivated within $5 \mathrm{~min}$. As shown in Fig. 6B, a similar trend was observed for $S$. typhimurium. In the absence of chlorine, the concentration of $S$. typhimurium increased from $3.1 \log$ to $6.5 \log$ during photoreactivation under fluorescent light. The addition of $1 \mathrm{mg} / \mathrm{L}$ chlorine was only adequate in inactivating bacteria in 10 minutes. After $10 \mathrm{~min}$, no residual chlorine was detected due to the rapid depletion of the chlorine, and the photoreactivation of $S$. typhimurium still occurred. At a dosage of $2 \mathrm{mg} / \mathrm{L}$ chlorine, photoreactivation did not occur, and $S$. dysenteriae inactivated within $10 \mathrm{~min}$. These results indicated that the combination of a low dose of UV and a low concentration of chlorine can effectively inactivate bacteria and inhibit the photoreactivation of UV-damaged bacteria.

\section{Conclusions}

Viruses (HRV-Wa, MS2, and T4) were more resistant to UV disinfection than the tested enteric bacteria. The UV inactivation rate was not affected by the quality of the waters that were tested. MS2 can be used as a conservative surrogate in 
UV disinfection. The UV-damaged pathogenic bacteria were significantly photoreactivated under fluorescent light irradiation. Moreover, the inactivated bacteria exhibited different photoreactivation rates with different water samples. The higher UV doses used in this study were able to inhibit photoreactivation of the bacteria. The combination of a low dose of UV and a low concentration of chlorine not only can inhibit the photoreactivation of UV-damaged bacteria but also can inactivate bacteria effectively.

\section{Acknowledgments}

This work was supported by the NSFC (20807051), the National 863 Project of China (2008AA062501, 2008AA06A414), and National Major Project of Science \& Technology Ministry of China (No.2008ZX07314-003, 2009ZX07424-003).

\section{Author Disclosure Statement}

No competing financial interests exist.

\section{References}

Bolton, J.R., and Linden, K.G. (2003). Standardization of methods for fluence (UV dose) determination in bench-scale UV experiments. J. Environ. Eng. 129, 209.

Frurta, M., Schrader, J.O., Schrader, H.S., Kokjohn, T.A., Nyaga, S., McCullough, A.K., Lloyd, R.S., Burbank, D.E., Landstein, D., Lane, L., and Van Etten, J.L. (1997). Chlorella virus PBCV-1 encodes a homolog of the bacteriophage T4 UV damage repair gene denV. Appl. Environ. Microbiol. 63, 1551.

Hu, X.X., Hu, C., Peng, T.W., Zhou, X.F., and Qu, J.H. (2010). Plasmon-induced inactivation of enteric pathogenic microorganisms with $\mathrm{Ag}-\mathrm{AgI} / \mathrm{Al}_{2} \mathrm{O}_{3}$ under visible-light irradiation. Environ. Sci. Technol. 44, 7058.

Jean, J., Blais, B., Darveau, A., and Fliss, I. (2002). Simultaneous detection and identification of hepatitis $\mathrm{A}$ virus and rotavirus by multiplex nucleic acid sequence-based amplification (NASBA) and microtiter plate hybridization system. J. Virol. Methods 105, 123.
Koivunen, J., and Heinonen-Tanski, H. (2005). Inactivation of enteric microorganisms with chemical disinfectants, UV irradiation and combined chemical/UV treatments. Water Res. 39, 1519.

Lima, A.A., Moore, S.R., Barboza, M.S., Jr., Soares, A.M., Schleupner, M.A., Newman, R.D., Sears, C.L., Nataro, J.P., Fedorko, D.P., Wuhib, T., Schorling, J.B., and Guerrant, R.L. (2000). Persistent diarrhea signals a critical period of increased diarrhea burdens and nutritional shortfalls: A prospective cohort study among children in northeastern Brazil. J. Infect. Dis. 181, 1643.

Montgomery, M.A., and Elimelech, M. (2007). Water and sanitation in developing countries: Including health in the equation. Environ. Sci. Technol. 41, 17.

Muellner, M.G., Wagner, E. D., McCalla, K., Richardson, S.D., Woo, Y.T., and Plewa, M. J. (2007). Haloacetonitriles vs. regulated haloacetic acids: Are nitrogen containing DBPs more toxic? Environ. Sci. Technol. 41, 645.

Quek, P.H., Hu, J.Y., Chu, X.N., Feng, Y.Y., and Tan, X.L. (2006). Photoreactivation of Escherichia coli following mediumpressure ultraviolet disinfection and its control using chloramination. Water Sci. Technol. 53, 123.

Quek, P.H., and Hu, J.Y. (2008). Indicators for photoreactivation and dark repair studies for following ultraviolet disinfection. J. Ind. Microbiol. Biotechnol. 35, 533.

Shannon, M.A., Bohn, P. W., Elimelech, M., Georgiadis, J.G., Marinas, B.J., and Mayes A. M. (2008). Science and technology for water purification in the coming decades. Nature 452, 301.

Simonet, J., and Gantzer, C. (2006). Inactivation of poliovirus 1 and F-specific RNA phages and degradation of their genomes by UV irradiation at 254 nanometers. Appl. Environ. Microbiob. $72,7671$.

Sommer, R., Pribil, W., Appelt, S., Gehringer, P., Eschweiler, H., Leth, H., Cabaj, A., and Haider, T. (2001). Inactivation of bacteriophages in water by means of non-ionizing (UV$253.7 \mathrm{~nm}$ ) and ionizing (gamma) radiation: A comparative approach. Water Res. 35, 3109.

Wolfe, R.L. (1990). Ultraviolet disinfection of potable water: current technology and research needs. Environ. Sci. Tech. 24, 768. 